\title{
Saúde e doença em aldeias Guarani: lidando com emoções
}

Elizabeth de Paula Pissolato*

\section{Resumo}

Este artigo toma por base a etnografia contemporânea sobre grupos Guarani e propõe uma abordagem das relações de parentesco e das emoções nos termos de constantes e complexas negociações intersubjetivas voltadas à produção de saúde e do estado referido como "estar alegre" (-vy' a). A ética do cuidado entre parentes define-se aqui pela produção de bemestar e disponibilização de habilidades de cura e evitação de processos agressivos (doença). Por outro lado, a lida com as emoções conecta-se diretamente com práticas de mudança residencial adotadas pelas pessoas quando não se sentem mais "alegres" ou suspeitam de agressões originadas no contexto em que vivem. Um jogo complexo que articula a percepção sobre as próprias aflições e impressões ou suspeitas quanto aos sentimentos e disposições de outras pessoas entra em cena, permitindo-nos uma abordagem das emoções como "estados intersubjetivos", mas também com implicações éticas e inscritas no social.

\section{Palavras-chave}

Guarani. Parentesco. Emoções. Saúde-doença.

\begin{abstract}
This article draws upon contemporary ethnography regarding Guarani groups and it proposes an approach on kinship relationships and on feelings in terms of persistent and intricate intersubjective negotiations focused on the creation of health and a state referred to as "being happy" (-vy 'a). The ethics of care among relatives is defined here as the creation of wellbeing and the providing of abilities of healing and avoidance of aggressive processes (illness). On the other hand, dealing with feelings directly connects to residential change practices adopted by people when they no longer feel "joyful" or become suspicious of aggressions stemming from the context in which they live. A complex game that articulates the perception of one's own afflictions and impressions or suspicions regarding feelings and dispositions of
\end{abstract}

\footnotetext{
* Elizabeth Pissolato é Doutora em Antropologia Social pelo Museu Nacional da Universidade Federal do Rio de Janeiro (UFRJ). Professora Associada do Programa de Pós-Graduação em Ciências Sociais (PPGCSO) e Departamento de Ciências Sociais da Universidade Federal de Juiz de Fora (UFJF). E-mail: elizabeth.pissolato@gmail.com.
} 
other people when they come into play, allowing us to approach feelings as "intersubjective states", but with ethical implications inscribed in social life.

\section{Keywords}

Guarani. Kinship. Emotions. Health-disease.

\section{Socialidades amazônicas e emoções}

O texto a seguir, que toma por base a etnografia contemporânea sobre coletivos Guarani ${ }^{1}$, pretende um diálogo principalmente em duas direções. Por um lado, visa a uma a proximação com abordagens recentes das emoções na etnologia amazônica, em conexão com temas consagrados nesse campo, como o parentesco e o ritual. Por outro lado, pretende também um diálogo, ainda que modesto, com perspectivas teóricas desenvolvidas no âmbito da antropologia das emoções.

A etnologia das sociedades indígenas sul-americanas, desde o final dos anos 1970, trouxe para o centro de suas reflexões a corporalidade (SEEGER; DA MATTA; VIVEIROS DE CASTRO, 1979). Mostrou como pensar a pessoa e o socius no continente implica tematizar a produção, transformação e destruição de corpos. Articulando parentesco e cosmologia, mostrou como o corpo ou a pessoa são relacionais - na definição de Viveiros de Castro (2002, p. 380): "feixe de afecções e capacidades" que lhe atravessam - corpo só apreensível efetivamente sob o olhar exterior de outrem (TAYLOR; VIVEIROS DE CASTRO, 2006) e estando marcado por uma instabilidade crônica (VILAÇA, 2005). Assim, seria preciso estar constantemente produzindo similaridade entre corpos de congêneres, através da comensalidade e outras práticas, já que há sempre um risco iminente de transformação noutros corpos/adoção de outros modos de

\footnotetext{
${ }^{1}$ Trata-se, principalmente, de etnografias desenvolvidas junto a grupos que ficaram conhecidos na literatura sobre os Guarani como Mbya ou Guarani Mbya. A definição de três subgrupos guarani - com diferenciações linguísticas e culturais - tal como proposta por Schaden (1962) ao considerar a presença Guarani em terras brasileiras (mas com correspondências no Paraguai, Argentina e Uruguai) é tema de um debate que não cabe desenvolver aqui. De todo modo, mantenho o uso do termo Mbya para identificar um conjunto de aldeias no Sul e Sudeste do Brasil, em que predominam falantes desse dialeto. A população Mbya no Brasil aproxima-se de 8.000 pessoas, distribuídas em uma centena de aldeias nos estados do Sul e Sudeste do país (excetuando-se Minas Gerais) e ainda com presença nos estados do Pará e Tocantins na região Norte (INSTITUTO SOCIOAMBIENTAL, 2016, 2018). Sobre minha experiência etnográfica e a produção recente de pesquisas junto aos e pelos Guarani, veja a sessão seguinte.
} 
vida/ aparentamento com outras gentes (FAUSTO, 2002, 2007; VILAÇA, 2002, entre outros).

A afirmação da centralidade do idioma da corporalidade na etnologia amazônica, de todo modo, desenvolveu-se sob diferentes ênfases. De um lado, um conjunto de análises tendeu a priorizar trocas entre o "interior" e o "exterior" da sociedade e temas como o xamanismo e a guerra, definindo a predação como modo de relação por excelência na cosmopolítica ameríndia, vertente que Eduardo Viveiros de Castro nomeou "economia simbólica da alteridade" (VIVEIROS DE CASTRO, 1996). De outro lado, abordagens fenomenológicas tenderam a aproximar a temática do corpo com a das emoções, focalizando, principalmente, valores normativos da socialidade e práticas de compartilhamento no nível doméstico (vertente chamada por aquele mesmo autor de "economia moral da intimidade" (VIVEIROS DE CASTRO, 1996). Os trabalhos dessa vertente destacam a "convivialidade" como modo de socialidade orientado por princípios "éticos" e "estéticos", a socialidade sendo aqui uma construção diária voltada à produção de parentescoehumanidade(GOW,2000;OVERING,1991;OVERING;PASSES, 2000 e outros). Se a primeira vertente, ao descrever processos agressivos entre diferentes humanidades (a humanidade aqui não se restringindo à espécie homo sapiens sapiens), desenvolveu análises sobre a questão da afinidade e da predação centrais para se pensar a socialidade amazônica, a segunda deu visibilidade e demonstrou a relevância de temas como o "viver bem", a ética do cuidado produtor de "saúde" e "tranquilidade", a importância do controle sobre certas emoções, o foco na produção de afetos no dia a dia. Aqui a socialidade remete diretamente a práticas intralocais, e o parentesco é definido como uma memória inerentemente afetiva. Assim, por exemplo, quando tratado nos termos de uma "consciência humana", que se desenvolve a partir da experiência de ouvir histórias contadas por parentes mais velhos (GOW, 1997).

Penso que a etnografia sobre povos Guarani nos permite um exercício interessante de análise sobre as emoções justamente ao trazer elementos próximos de uma e outra dessas abordagens, que, afinal e com certeza, não devem ser tomadas como autoexcludentes. De um lado, o parentesco Guarani se define como prática rotineira de um conjunto de cuidados produtores de saúde e bem-estar. Trata-se de uma variedade de práticas terapêuticas, podendo o próprio xamanismo ser assim definido. De outro lado, constatamos o valor central da hostilidade no mesmo campo do parentesco (e afinidade), e sua potencialidade para fazer adoecer ou mesmo matar. 
O que pretendo demonstrar neste artigo é como a atenção aos processos corporais (físico-emocionais) desdobrados em saúde-satisfação ou doençainsatisfação corresponde a uma atividade cotidiana de caráter delicado praticada nas aldeias Guarani Mbya, vinculada à incerteza constante sobre a natureza dos sentimentos que os outros nutrem por alguém. Essa incerteza, que põe em jogo constantemente as emoções como estados intersubjetivos (WILCE, 2009), mobiliza, como veremos, o desejo de sair/buscar outro contexto de vida, conhecer o que pode vir adiante no "caminho", como costumam dizer nossos interlocutores indígenas, acenando suas expectativas de um possível "caminho bom-bonito", tape porã. Para além de uma definição do parentesco como memória afetiva do vivido, tal como referido, os afetos remetem também aqui à abertura no tempo e espaço implicada na realização do parentesco. Em outras palavras, é possível buscar novos lugares e alternativas para reanimar ou reemocionar a vida.

\section{Aproximações etnográficas}

Os desenvolvimentos propostos adiante partem, primeiramente, de minha experiência de pesquisa de doutorado, quando vivi em companhia de minha filha, por cerca de 18 meses, entre 2001 e 2004, nas aldeias de Araponga e Parati Mirim, próximas à cidade de Parati, no Rio de Janeiro, viajando para outras áreas mbya em São Paulo e no Paraná com nossos anfitriões nessas aldeias ${ }^{2}$. Muitos temas que compuseram a etnografia (PISSOLATO, 2007) foram retomados em momentos posteriores de pesquisa no âmbito de grupos técnicos para atualização de limites de Territórios Indígenas Mbya (entre 2007 e 2009) e outros contextos que me propiciaram a convivência nessas e outras áreas habitadas por famílias guarani. Tais temas tomaram forma, desde a tese, na articulação entre dimensões do parentesco, que jamais se separam de uma atividade xamânica mais ou menos especializada, mas sempre voltada para a produção de saúde-do "estar bem" (-iko porã), que não deixam de estar ligadas, por sua vez, à movimentação constante

\footnotetext{
${ }^{2}$ Ao longo desse período, eu e Nina, que começou a temporada ainda com seus 7 meses de idade, vivemos inicialmente em uma casa a meio caminho dessas Terras Indígenas, na Vila de Patrimônio, posteriormente nos mudando para as aldeias, passando a acompanhar as rotinas das famílias que nos acolheram generosamente em suas casas, o casal Augustinho e Marciana e depois Ilda em Araponga; Cleonice, Elio e sua família em Parati Mirim. A vida ali com minha filha, com os aprendizados em que me iniciava nos cuidados de uma criança, levou-me a diversas matérias acerca do parentesco, da produção de saúde, dos processos pessoais. A pesquisa deu origem à tese, defendida em 2006, no Museu Nacional (UFRJ) posteriormente publicada (PISSOLATO, 2007).
} 
de pessoas e grupos de parentespor lugares diversos, aspecto que muitos estudos sobre os Guarani, a partir de diferentes enfoques, desenvolveram (MELIA, 1991, 1992; GARLET, 1997; LADEIRA[1992]2007, entreoutros).

As três últimas décadas são marcadas por um crescimento notável da pesquisa etnológica com coletivos Guarani presentes no Sudeste, no Sul e no Norte do país. Também se intensifica a produção de estudos sobre os Kaiowa e Guarani concentrados em Mato Grosso do Sul. Particularmente importante nesse período é o desenvolvimento de pesquisas realizadas pelos próprios indígenas,com a produção de trabalhos acadêmicos e outros textos (BENITES, 2012, 2014; JOÃO, 2011; PESQUISADORES GUARANI, 2013, entre inúmeros outros), assim como filmes etnográficos e a participação em fóruns de debates em antropologia. De modo geral, podemos afirmar que nessas décadas, a pesquisa (com) Guarani aprofundou o diálogo com a etnologia sobre povos amazônicos e de outras regiões, e assumiu um lugar central no desenvolvimento de temas ameríndios, como o das formas políticas ou as cosmopolíticas ameríndias.

Neste artigo, refaço caminhos propostos na abordagem referida, partindo da conexão entre parentesco, xamanismo e mobilidade, aqui, contudo, buscando uma aproximação maior com as emoções. Ainda que minhas impressões em campo naqueles anos e nos subsequentes sejam o ponto de partida, muitos dos temas aqui tratados, voltados à análise da pessoa e da socialidade mbya, foramdesenvolvidos e continuam sendo explorados nos trabalhos de um número cada vez maior de pesquisadores dedicados aos Guarani, antropólogas e antropólogos, indígenas e não indígenas, produção a que, por sua grande extensão, apenas parcialmente poderei me referir.

\section{Corpo e emoção}

Como já foi observado, para diferentes povos ameríndios, o nascimento de uma criança não atesta, desde o início, a sua humanidade, uma série de práticas sendo necessárias para torná-la efetivamente congênere daqueles que a recebem. Etnografias sobre povos diversos no continente fazem referência a massagens, amuletos, ao uso de pintura corporal e outras técnicas aplicadas em recém-nascidos com essa finalidade (CLASTRES, [1972]1995, p. 15 para os Guayaki; VIVEIROS DE CASTRO, 1986, p. 442, para os Araweté; FAUSTO, 2001, p.396, para os Parakanã). 
Nas aldeias Guarani aqui tratadas o que se destaca é a busca de maneiras capazes de "alegrar" a criança, e convencê-la a ficar entre seus parentes terrenos. O investimento faz pleno sentido na medida em que a vida entre parentes pode ser mesmo referida como "alegrar[em]-se mutuamente" (PEREIRA, 2014, p.60). Recebendo seu nhe'ë ("alma palavra") de pais divinos que o enviam à Terra, a criança nem sempre se contenta na nova vida e quer ficar ${ }^{3}$, de modo que suas manifestações são objeto de cuidadosa atenção. Mesmo antes do nascimento, os comentários demonstram a ênfase dada aos sentimentos da criança. Esta poderia, como dizem, não gostar do comportamento da mãe e/ou do pai durante a gestação, não se dispondo a permanecer entre eles. Desde esse momento e logo após o nascimento, então, relações intersubjetivas entre o recém-nascido e os parentes que o acolhem estão em questão, e buscam-se modos de produzir satisfação ou de manifestação, por parte do bebê, de sua disposição para "ficar". Assim percebe-se o "mamar bem" (-kambu porã), atenta-se a possíveis desconfortos e particularmente ao choro, que deve ser evitado quando em excesso; assim também se busca o estímulo à comunicação em gestos, sorrisos e nos primeiros ensaios de fala da criança. Mais adiante, o investimento para alegrá-la continua com a alimentação posta diretamente em sua boca pelas mãos da mãe, nos estímulos a pequenos saltos no colo segurando-a pelos braços, na procura de um xamã que "escute seu nome" ${ }^{4}$, na construção de seu, $a m b a$, uma fileira de estacas fixadas nas proximidades da casa onde a criança irá aprender a se erguer e dar seus primeiros passos ${ }^{5}$.

Por ocasião do nhemongarai, quando as crianças pequenas têm seus nomes divinos revelados, novamente o aspecto da satisfação vem à tona. Em alguns casos, quando o xamã diz aos pais não ter "escutado" o nome de seu filho ou filha, ouvimos comentários sobre o possível desejo de "não

\footnotetext{
${ }^{3}$ Próximo ao nascimento, o nhe'ë encontra-se ainda pouco assentado na pessoa e uma série de cuidados devem ser tomados para que se acostume na Terra e também para que não se perca (por exemplo, na mata, quando vai atrás do pai quando este se afasta de casa). Desde Schaden (1962, p. 113), esse ponto é desenvolvido em diversas etnografias (MELLO, 2006, pp. 149-150; PISSOLATO, 2007, pp. 280-281; MENDES JUNIOR, 2016, p. 53, entre outros).

${ }^{4}$ Os nomes divinos são "escutados" durante o nhemongarai, ritual que "batiza" as primeiras colheitas do milho Guarani referido como avaxiete ("milho verdadeiro") e/ou a erva mate, ka'a, reunindo frequentemente moradores locais e visitantes de outras aldeias em noites sucessivas de reza-canto.

${ }^{5} \mathrm{O}$ "levantar" (-puã) e "caminhar" (-guata), e mais adiante, o "dançar" (-jeroky) são fundamentais à vida guarani na Terra. Desde Cadogan (1959) e sua abordagem da "verticalidade" como condição de existência, às etnografias contemporâneas com foco na produção do parentesco, bem como à mobilidade guarani, os dois primeiros termos são amplamente explorados.
} 
ficar" da criança, e, no caso daquelas que não se mostram saudáveis no início da vida, é possível que recebam nomes distintos em rituais subsequentes, na expectativa de que o novo nome por que será chamada, enfim, a alegre. Como definiu Pereira (2014, p.61), "ter alegria para viver tal e qual se vive entre parentes é uma afecção corporal positiva". E, podemos acrescentar, valem todos os esforços para produzi-la ${ }^{6}$.

Já desde essa fase, um modo muito valorizado de produzir satisfação ou alegrar a criança realiza-se no alimentar, -mongaru. Como observou Marilyn Strathern (1988, p.251) a alimentação é uma relação. Entre os povos amazônicos de modo geral, mas certamente muito além desse contexto, trata-se de uma das práticas mais fundamentais na construção de relações de parentesco. Conforme Taylor e Viveiros de Castro (2006, p. 161): “Oferecer alimento de forma regular com marcas de afeição [seria] o primeiro passo para a construção mútua de uma corporeidade compartilhada [dando também] acesso ao que seria a primeira forma de consciência, aquela do "pensar aos próximos".

Muitas etnografias realizadas no continente chamaram a atenção para o lugar central da partilha de alimentos na produção da socialidade e afirmaram a comensalidade como aspecto-chave do aparentamento (GOW, 1991; VILAÇA, 1992; OVERING; PASSES, 2000; FAUSTO, 2002, entre outros). Dar de comer e comer junto - a mesma comida - são práticas que definem, na base, o que vem a ser a relação entre parentes.

Voltando ao -mongaru nas aldeias guarani mbya em que convivi, um aspecto que me pareceu interessante foi a atenção aos gostos pessoais. $\mathrm{Na}$ tentativa de alegrar suas filhas e filhos, pais se deslocavam até as cidades para comprar guloseimas ou ingredientes necessários à preparação de um certo item culinário a partir de um desejo manifestado pela criança. $\mathrm{O}$ mesmo vemos, a propósito, no contexto da caça, quando um homem vai atrás de certa presa para satisfazer o desejo de comê-la manifestado por sua esposa ou outro parente para quem, então, ele caça (FERNANDES MENDES JR., 2009). Desde cedo, a culinária nas aldeias mbya também cumpre o papel de satisfazer desejos e dar atenção aos gostos pessoais daqueles para quem se cozinha (PISSOLATO, 2007, p.190).

${ }^{6} \mathrm{O}$ lugar central da alegria na socialidade tem sidotema constante na etnografia desenvolvida em diferentes contextos Guarani (PISSOLATO, 2007; HEURICH, 2011; PIMENTEL, 2012; PEREIRA, 2014; ARANHA, 2018, entre outros). 


\section{Parentesco curativo}

Como já foi possível perceber, o estado de quem "fica alegre" coincide com a condição saudável da pessoa. Crianças pequenas que não "demonstram" estar contentes, que choram constantemente e se mostram fisicamente frágeis acenam que "não vão ficar". Mas os esforços para seduzi-las a ficar não cessam facilmente. E aqui encontram-se parentesco e xamanismo.

$\mathrm{O}$ cuidado entre parentes, e, neste caso, de crianças que se pretende tornar parentes, compreende uma série de práticas terapêuticas mais ou menos especializadas. Em algumas situações, os pais modelam partes dos corpos de recém-nascidos, como o crânio, o nariz, as orelhas (SANTOS, 2017, p. 145) ou outras partes que desejem "arrumar" (-moatyrõ) (PEREIRA, 2014, p. 62). Pais e mães "enfumaçam" (-moataxi) $)^{7}$ o cocoruto, o peito e outras partes do corpo de suas crianças desde os primeiros meses de vida. Podem também levá-la, se julgarem necessário, a especialistas de sua confiança (muitas vezes, em viagens a outras aldeias) que sabem curar através do uso intensivo de tabaco (petÿ) nas sessões rituais de canto-reza. Quando julgarem o momento, buscarão um desses xamãs, como já referido, para a escuta no nome com que passarão, então, a chamar a criança.

Nessa fase, mas também em muitas situações de desconforto ou doença ao longo da vida, tais especialistas serão buscados em suas "casas de reza" (opy) para a identificação de causas para aflições que persistem e a extração (por sucção) de doenças que se instalaram em partes do corpo da pessoa afligida na forma de pequenas pedras, paus, chumaço de cabelo ou outros objetos.

Mas, em se tratando de especialidades terapêuticas, elas podem ser muitas, e costumam distribuir-se entre homens e mulheres que são procurados, então, para colaboração conforme as habilidades que se thes reconheçam: saber "achar" e aplicar "remédios do mato" (poã ka'aguy) no tratamento de diversos males ou na produção de agilidade e força (PESQUISADORES GUARANI, 2015, p. 24-25), fazer "benzimentos" para reverter alguns eventos específicos de doença; saber "aconselhar bem". Neste sentido, a palavra é ela mesma terapêutica. Como comentou um interlocutor de Adriana Testa (2014, p. 144): “[....] Quando o xeramõi ["rezador" fala], é também um remédio. Se uma pessoa está triste ou preocupada, nossa palavra serve para tratar a pessoa [...]". Por outro lado,

\footnotetext{
${ }^{7}$ Com petÿgua, cachimbo de uso geral nas aldeias guarani, central nas práticas terapêuticas e no ritual de canto-reza, mas também usado em reuniões de cunho político, com presença de outras aldeias e de jurua (brancos).
} 
como veremos adiante, processos aflitivos podem ter origem em falas e outros fazeres de corresidentes.

Podemos dizer que a ética do cuidado entre as pessoas Guarani se liga diretamente à produção de saúde. Fazer parentesco é disponibilizar as próprias capacidades terapêuticas/de cura em sentido amplo para aqueles que se quer tornar ou tratar como parentes. É também apostar nas capacidades (curativas) das pessoas relacionadas, particularmente os mais velhos, chamados tamõi ou xe ramõi (usando-se aqui a $1^{\mathrm{a}}$. pessoa: "meu avô") e xe jaryi ("minha avó"). A propósito, o xamanismo como função se liga diretamente à condição de quem encabeça um grupo de descendentes. Ou seja, espera-se desses "avós" que ajam efetivamente como cuidadoresorientadores dos descendentes que vivem próximos a eles, ainda que não dominem todas as habilidades produtoras de saúde mencionadas. Podem ser ou não opita'i va'e (aqueles que tratam com tabaco), podem liderar ou não rituais na opy, a "casa de reza". De todo modo, deverão aconselhar e orientar os que permanecem junto deles.

A propósito, a fala merece aqui uma atenção especial. Tal qual destacado na abordagem da ética do cuidado entre diversos povos amazônicos (GOW, 1997; OVERING; PASSES, 2000), a fala é um dos lugares de maior investimento ético e estético no cotidiano das aldeias mbya. Desde a conversa informal até os discursos cerimoniosos feitos pelos mais velhos; no contexto das visitas cotidianas, encontros nas trilhas entre casas, na reunião matinal de um grupo de parentes em torno do fogo de chão que prepara o mate $\left(k a^{\prime} a\right)$ ou nas reuniões coletivas na opy, palavras merecem cuidado.

É possível reconhecer alguns gêneros de fala e elaborações estéticas que lhes são próprias. Assim, a fala ritmada e persistente acompanhada pelo andar nas sessões formais de aconselhamento; a "saudação" de um visitante que chega a uma aldeia e deve "contar" sobre seu caminho até ali e suas intenções; a narrativa de passagens míticas com marcações de intensidade em sílabas prolongadas num estilo que produz grande envolvimento dos que escutam; além da fala ritual conhecida como nhe'ë porã ou ayou porã, chamada também de "linguagem da opy", com seu léxico repleto de imagens metafóricas, usada no contexto ritual quando se fala das e às divindades.

Contar (-mombe'u) é um verbo que compreende muitas possibilidades, entre as quais contar histórias do tempo referido como yma ("antigo"), comentar acontecimentos vistos em sonho (-exa $\left.r a^{\prime} u\right)$ ou falar de algum desconforto que se sente. Nestes casos, conta-se na expectativa de ouvir alguma palavra (acolhedora-orientadora) em retorno. É aqui que gostaria 
de começar a me aproximar de alguns aspectos da relação entre fala e emoção e do caráter ético das emoções (cf. adiante).

O cuidado com a fala envolve tranquilidade e comedimento, já que falas podem, muitas vezes, produzir antipatia ou raiva. Não cabe falar em excesso ou de modo impositivo. Cadogan (1959, p.39) refere-se à forma de "aconselhar discretamente repetidas vezes" como o modo apropriado de se falar aos filhos e filhas, conforme teriam feito os Nhamandu Ru Ete, os "primeiros pais das palavras-almas" quando do envio de seus filhos à Terra. Nas aldeias contemporâneas, o tema da moderação é constantemente destacado por xamãs (TESTA, 2014, pp.144-145; ARANHA, 2018, pp.291292, entre outros). A propósito de seus tratamentos, inclusive, estes dizem que só interferem nos processos de doença oferecendo conselhos ou outros tratamentos no caso de as pessoas envolvidas buscarem sua ajuda. E, ainda, qualquer "tratamento xamânico" começa pela demanda à pessoa que veio em busca de auxílio para que "conte" sobre o próprio estado.

Saber ouvir e falar são parte de uma "estética cotidiana" (OVERING, 1991) complexa. De um lado, não cabe antecipar-se ao "contar" de alguém; de outro lado, não devemos ouvir e nos calar diante de alguém que vem contar algo. A expressão "tei ke reiko rive", que pode ser traduzida como "tem que ficar apenas [não ligar]" - expressão que escutei de uma mulher que instruía sobre como deve ser o comportamento nas aldeias mbya (PISSOLATO, 2007, pp. 168-169) - parece indicar que não cabe irritar-se/ incomodar-se com o que se ouve. Mas certamente não ao ponto de ignorar o que possa estar afligindo alguém.

Enfim, contar e ouvir são disposições e modos de agir fundamentais à construção da relação entre parentes e ao que se desdobra daí para a produção do "estar bem", -iko porã, que, como temos visto, remete simultaneamente àquela disposição físico-emocional dita -vy' a, "alegre", e ao fortalecimento da saúde.

Inversamente, doença e propensões a males diversos, mba'eaxy ${ }^{8}$, vinculam-se diretamente ao estado referido como ndovy'ai ("não alegre", literalmente), associado frequentemente a "saudade" (-exa nga'u), à indisposição para a convivência, a antipatias e suspeitas sobre as disposições de outra(s) pessoa(s) que vive(m) junto. ${ }^{9}$

\footnotetext{
${ }^{8}$-Axy pode ser traduzido como "dor", "doença", estando presente também em tekoaxy ou yoyrekoaxy, na referência à vida terrena como marcada por manifestações de "dor", "doença".

${ }^{9}$ Situações de convivência estão, da mesma maneira, na origem dos estados ditos nhemyrõ e $v y^{\prime} a e^{\prime} y$, associados aos eventos de "suicídio" entre os Guarani e Kaiowá em Mato Grosso do Sul. Pimentel (2006)
} 


\section{Emoções como estados intersubjetivos}

Doenças são propriamente agressões enviadas por humanos e não humanos. Podem vir em ventos ditos "maus-feios", yoytu vai, lançadas na forma de objetos invisíveis por donos mestres de espécies não humanas ou de lugares como as matas, rios, cachoeiras ${ }^{10}$, que, conforme dizem nossos interlocutores, costumam "não gostar" quando alguém se aproxima de seus domínios. Em contraste com doenças comumente chamadas "doença de jurua (branco)", processos agressivos como os referidos, bem como aqueles originados pela antipatia, indisposição ou mesmo intenção declarada por algum humano de "fazer mal" a outro, são normalmente persistentes e tratáveis apenas por xamãs experientes e de modo continuado. Essas são as chamadas "doenças espirituais" ou "doenças de Guarani", que focalizarei neste texto exclusivamente nos casos em que decorrem de contextos relacionais entre pessoas mbya.

Novamente encontramos aqui temas comuns a vários povos ameríndios, como a definição de doença e morte como processos nunca "naturais", mas sempre provocados por alteridades diversas, e a feitiçaria como forma de agressão entre humanos que faz adoecer e pode levar à morte. Se pouco tratada na literatura clássica sobre grupos Guarani, a feitiçaria revela-se, especialmente na etnografia mais recente sobre esses grupos, como tema central da socialidade (PISSOLATO, 2007, pp. 198-211; PIMENTEL, 2012, pp. 169-171; TESTA, 2014, pp. 69-70, 73-74, entre outros).

Contrapartida da ética do cuidado entre parentes, a feitiçaria aparece explicitamente em relatos sobre doenças de longa data já diagnosticadas e também em diagnósticos atuais por xamãs que associam explicitamente processos aflitivos daqueles que tratam com situações de vida em geral localizadas a certa distância no espaço e no tempo(CHASE-SARDI, 1992, pp. 94-97 , PISSOLATO, 2007, pp. 198-211; PEREIRA, 2014, p.192). Relações conjugais desfeitas em aldeias onde se viveu anteriormente são causas muito comuns desses males, mas é preciso notar que tais diagnósticos abrem espaço logicamente para suspeitas ou mesmo acusações explícitas em contextos atuais.

\footnotetext{
${ }^{10}$ A maestria apresenta-se como um "modo generalizado [entre ameríndios] que caracteriza interações entre humanos, entre nãohumanos, entre humanos e nãohumanos e entre pessoas e coisas" (FAUSTO, 2008). Na etnografia sobre grupos Guarani, os donos não humanos,

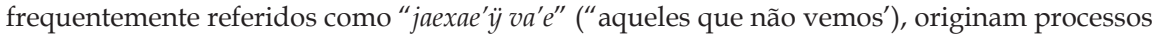
agressivos produtores de doença ou, ainda, podem seduzir (sexualmente) humanos em processos de transformação animal ditos -jepota.
} 
Na prática, suspeitas de feitiçaria podem surgir no interior de um grupo de parentes que vivem juntos, sejam afins ou consanguíneos, na desconfiança sobre o "mau" uso de capacidades xamânicas por certos especialistas ou, ainda, em situações de conflito entre grupos de parentesco que vivem em aldeias vizinhas. Um dos aspectos mais importantes no cuidado da saúde (própria e/ou também de familiares) diz respeito, portanto, à percepção dos riscos de doença e até de morte desdobrados dos contextos relacionais que se experimenta.

As emoções aqui assumem um lugar crucial, já que os processos de adoecimento (assim como os de fortalecimento da saúde) se revelam como estados emocionais - sentidos no corpo - experimentados pelas pessoas. Dizendo de outro modo, sentir-se mal coloca em questão o sentimento de pessoas corresidentes, suas possíveis antipatias ou outros "maus" sentimentos e pensamentos capazes de desencadear aflições.

Isto nos leva a uma definição das emoções como "estados intersubjetivos" (WILCE, 2009, p.8), contrários à separação entre estados internos à pessoa e a dimensão da interação social (v. também ALLARD, 2013).

Estados intersubjetivos que se desdobram em saúde-satisfação ou descontentamento-doença conectam, nos contextos guarani aqui tratados, uma atividade perceptiva fina e constante sobre os próprios estados experimentados e também sobre as disposições e estados daqueles que vivem perto. Como veremos adiante, a prática de deslocamento, com passagens por diferentes aldeias ao longo da trajetória de vida das pessoas, define-se como estratégia das mais eficazes no trato das emoções e da saúde. Mas, antes de passar aos deslocamentos, fiquemos um pouco mais nas emoções.

Muitos dos estados doentios de crianças são interpretados como "saudade" do pai ou da mãe que deixou a aldeia em que viviam juntos, para uma viagem ou mudança definitiva para outras aldeias. Por "tristeza" ou "saudade" do marido ou esposa falecidos, uma mulher ou homem podem ter a saúde seriamente comprometida, razão por que, neste caso, muitos optam por deixar o lugar onde viviam com seus cônjuges quando vivos. Aqui as emoções são explicitamente associadas à falta de um parente, à ruptura de uma relação. Mas outros sentimentos também podem ganhar forma na referência ao modo de agir de parentes corresidentes. Assim, por exemplo, na queixa de que "os próprios parentes não [lhe] cuidam" feita por alguém.

Peter Gow (2000) fala do sentimento de "desamparo" como estando na 
base da produção de parentesco entre os Piro: as pessoas vêm ao mundo sozinhas, desamparadas, a relação de parentesco sendo propriamente a do dar amparo, acompanhada do sentimento de "compaixão", "consolo" (em relação ao sofrimento de outrem). A ética do "viver bem" produz aqui um cotidiano que o autor, de início, considera algo desestimulante ou mesmo enfadonho, como que marcado por um "não acontecer nada" ou "não se fazer nada" que, afinal, ele compreenderá nos termos da afirmação de que basta se "viver junto" [não sendo preciso mais nada] para se "viver bem".

Fazendo um paralelo com esse povo que habita a Amazônia peruana, podemos dizer que nas aldeias guarani que focalizamos não sentir-se bem coloca justamente a questão da possibilidade de sair ou de "ir embora", buscando-se alternativas residenciais junto a parentes que vivem noutras aldeias ${ }^{11}$. Por sua vez, tais intenções de ir embora podem produzir novas instâncias de negociação interpessoal, o que se liga diretamente às escolhas entre "falar" e "não falar" (v. a seguir).

Contudo, nem sempre, os estados intersubjetivos se revelam como efeitos evidentes das relações vividas, de modo que a atividade perceptiva (que poderíamos chamar, em certa medida, subjetiva) é matéria de grande complexidade e sempre aberta a interpretações múltiplas. O que se vê em sonhos (-exa $\left.r a^{\prime} u\right)$, o que se percebe em "visões" como impressões "más-feias", sensações de desconforto físico, ou mesmo o desânimo para conversar, brincar, ou seja, para a convivência local, assim como a sensação que me foi traduzida uma vez por um jovem como "estar pensando longe", todos esses são estados que devem ser acompanhados com cuidado em seus desdobramentos, acompanhamento que, por sua vez, também mobiliza pessoas relacionadas. Ou seja, aqui também a ética do cuidado entre parentes não deixa de estar presente, ainda que se veja limitada na decisão que pode ser tomada e que, conforme a mesma ética, não cabe impedir: a de deixar o lugar e os parentes ali.

\footnotetext{
${ }^{11} \mathrm{O}$ parentesco mbya realiza-se aqui em um universo multilocal de parentes, distribuídos em dezenas de aldeias ao longo do vasto território ocupado pelos Guarani, as quais se mantêm conectadas através da circulação de pessoas e de informações umas sobre as outras (sobre a multilocalidade mbya, veja-se PISSOLATO, 2007, pp.211-217). Mudar de lugar parece estar efetivamente no centro das cosmopolíticas Guarani. Pimentel (2012, p. 137) observa, sobre o regime da vida nas reservas em Mato Grosso do Sul, como "ficar parado" aípode ser realmente insuportável.
} 


\section{Lidando com emoções}

Vimos no início deste texto como a relação entre parentes caracteriza-se pelo cuidado mútuo voltado à produção de saúde e do "ficar alegre". Vimos ainda como a definição de "viver bem" aqui se liga diretamente ao convívio marcado pela partilha de comida e de conversas aconselhadoras, mas não impositivas, temperadas de um certo humor que alegra sem incomodar. Mas, como também observamos, nem sempre a vida em comum produz satisfação e bem-estar. Viver junto pode produzir indisposições, antipatias ou mesmo "raiva" (-ipoxy), estados que se manifestam naquela instabilidade do corpo já mencionada. Noutras palavras, como comentou certa feita um tamoi amigo, é possível acordarmos bem e com boa disposição numa manhã, e, já na tarde deste mesmo dia, não nos sentirmos mais assim.

A instalação de um mal-estar, na verdade, traz à tona uma complexa negociação intersubjetiva. Ao mesmo tempo em que a aposta nas habilidades de corresidentes faz com que se busque o seu auxílio, o estado de aflição coloca também em questão os sentimentos-disposições-agires dos mesmos corresidentes.

Há aqui um complexo jogo intersubjetivo e manejo de emoções. E novamente a fala - ou sua ausência - entra em cena. Manifestações pessoais quanto ao desejo de deixar o local atual de residência tendem a produzir efeitos sobre as emoções de pessoas relacionadas. Queixas de parentes, como na frase já mencionada, afirmando que esses "não cuidam" (daquele ou daquela que sofre por isto), às vezes enfatizadas com expressões como o "sentir [tal descuido] no coração" poderiam ser definidas aqui como uma forma de ação ética, no sentido que define Allard (2013, pp. 546-547) para contextos de lamentação e choro pelos mortos entre os Warao, povo que vive na Amazônia venezuelana. Atitudes como estas estão diretamente relacionadas à ética do cuidado entre parentes, e, ao serem postas em prática, não o seriam simplesmente para afirmar valores, mas corresponderiam a uma modalidade complexa de ação social, em quese coloca a questão da eficácia. Como sugeriu Lambek (2010 apud ALLARD, 2013, p. 547), o estudo da ética deveria ultrapassar o nível discursivo e institucional (das normas) e situar-se na articulação ambígua entre atos - como os de prometer, perdoar, reconhecer etc.) e as práticas em questão.

Uma fala queixosa como a citada pretende ter alguma eficácia ética, então, sobre os que a ouvem. Aqueles que pretendem "cuidar" e manter junto de si quem se sente assim tenderão a buscar palavras e outras maneiras para 
dissuadir o/a afligido/a de sua intenção. Um investimento semelhante dá-se, afinal, idealmente para toda e qualquer situação de indisposição, descontentamento: buscam-se modos de "reanimar", fazer de novo "ficar alegre" quem não demonstra satisfação e bem-estar.

Mas nem sempre são reveladas as impressões e sentires, mesmo entre pessoas de convivência muito próxima. Assim, por exemplo, na separação de casais em que, não raro, a estratégia da "fuga", sem nenhum aviso, é posta em prática (PISSOLATO, 2016). Fugir (-java) deixando deste modo a esposa ou o marido, sem explicação ou conversa, pode se ligar à intenção explícita de envolvimento em nova relação, quando se foge com alguém que ali também residia. $\mathrm{Ou}$, noutras vezes, pode corresponder simplesmente ao modo escolhido para abandonar uma relação conjugal ou uma convivência com afins que se tornam indesejáveis ${ }^{12}$.

O que se desenrola a partir da fuga de alguém não é matéria de fácil tratamento, em todos os sentidos. Não se sabe ao certo o que pode se desencadear a partir daí, seja enquanto atitudes, sentimentos ou processos aflitivos envolvendo aqueles que antes viviam juntos. O silêncio de quem sai pode evitar enfrentamentos diretos ${ }^{13}$, mas não é capaz de prevenir absolutamente as "doenças espirituais" já mencionadas; a tristeza (ndovy'ai), o ciúme (akãte'ÿ) ou a raiva (ipoxy) de quem foi deixado são estados potencialmente produtores de "mal-estar". Para além dos sentimentos mais ou menos tornados evidentes dos ex-cônjuges diretamente envolvidos, tais situações também colocam em foco a atenção a crianças que, nesses processos, se separam de seus pais ou mães e a percepção de parentes próximos, especialmente os mais velhos e experientes, acerca da situação. Enfim, uma configuração complexa de emoções-e-agires entra em cena. Não teremos espaço aqui para acompanhar etnograficamente tal complexidade, mas cabe dizer que são diversas as posturas e escolhas pessoais nesses casos. Há os que "vão atrás" e tentam "trazer de volta" seu cônjuge de uma outra

\footnotetext{
${ }^{12}$ Uma questão importante aqui é a dos desdobramentos desses eventos para a prole. Em muitos casos, crianças são também deixadas pelo pai ou mãe que vai embora. Na prática, há variações: por exemplo, uma mulher que deixa o marido pode resolver levar consigo seus filhos menores e deixar os mais velhos; pode deixá-los todos com uma avó que assuma o cuidado; a mulher pode ir embora com a expectativa de buscá-los mais tarde etc. A saúde das crianças e as disposições daqueles que assumirão seus cuidados tomarão igualmente parte nos eventos que sucedem a "fuga", cf. a seguir.

${ }^{13}$ Noutras situações podem, inclusive, assumir a forma de hostilidade aberta e levar ao homicídio, a hostilidade também se insinuando em ocasiões em que alguém admite seu estado de "ciúme" (akate'ÿ) ou "raiva" (ipoxy) e demanda ao cacique local que "mande embora" o visitante ou a visitante que estariam na origem desses estados.
} 
aldeia, os que demonstram profunda tristeza e passam a ser cuidados com afinco por seus parentes, os que dizem "não ligar" ou "não ter ciúme" do parceiro ou parceira que foi embora. Mesmo que ninguém declare nesses eventos abertamente "raiva" ou, mais ainda, "enfurecimento" (-gueropoxy), os efeitos agressivos desses estados não deixam de ser considerados, como vimos ao tratar do diagnóstico de doenças persistentes por xamãs.

\section{Emoções, corpo, transformações}

Alguns desenvolvimentos importantes no campo da antropologia das emoções têm buscado superar dicotomias marcantes no tratamento destas, como a tendência a associá-las exclusivamente ao polo da biologia (e psicologia) ou da cultura ou ainda distinguir e separar significado e sentimento, mente e corpo, indivíduo e grupo. Tomarei a seguir, para um diálogo ainda muito inicial com temas guarani tratados neste artigo, alguns desses desenvolvimentos.

Leavitt (1996, p. 524) fala de "corpos humanos sociologizados", corpos que agem em contextos de interação em situações vividas em grupo. As emoções, comorespostas a essas situações, seriam "experiências aprendidas e expressas no corpo em interações sociais via mediação de sistemas de signos verbais e não verbais" (p. 526). Assim, não passariam necessariamente pela consciência.

Michelle Rosaldo (1984) também nos aproxima dessa abordagem das emoções como sentidas em experiências corporais. Sua etnografia junto aos Ilongot, e particularmente a análise da noção de liget ("energia e paixão") associada ao coração como lugar de conexão entre pensamentos e sentimentos, permite-lhe definir uma dimensão corporal das emoções. Conforme Rosaldo (1984, p.143): “[as emoções são] pensamentos de alguma forma 'sentidos' em rubores, pulsações, movimentos de nossas vísceras (...) são pensamentos incorporados, pensamentos formados com a apreensão de que 'estou envolvido'".

Rejeitando a separação entre mente e corpo, consciência e sentimento, esses autores desenvolvem a noção de "embodiment", aproximando os pensamentos da experiência da vida afetiva, ou do sentir no corpo.

No contexto que aqui tomamos em análise, temos visto que não apenas emoções são sentidas no corpo, mas experiências traduzidas como "ficar alegre" ou "não ficar alegre", ou ainda como sentir "saudade" ou "raiva" são efetivamente capazes de produzir transformações corporais, mais ou 
menos objetivadas (já que a noção de mba'eaxy compreende desde um mal-estar que se insinua até a doença instalada na forma de objetos que o xamã deve extrair), ora fortalecendo a "saúde", ora se desdobrando em "doença", e isto não apenas para quem "sente", mas com consequências também, como vimos, para as pessoas diretamente envolvidas na origem/ produção desses estados. Noutras palavras, não é apenas a própria saúde que se coloca em questão.

Isto nos leva a um debate importante na etnologia ameríndia acerca do que é um corpo. Definido fundamentalmente por seu caráter relacional, um corpo só se revelaria aqui sob um outro "olhar" (TAYLOR; VIVEIROS DE CASTRO, 2006), não havendo corpos em si nem individualidades, ou, como afirmou Anne Christine Taylor, o "eu" [sendo] um estado altamente instável (TAYLOR, 1996). Não há como aprofundar aqui o debate sobre a noção de corpo, mas cabe notar a complexidade na abordagem das emoções como estados intersubjetivos e a instabilidade dos estados das pessoas que se lhe associa. O que sugiro é, então, que, entendendo o corpo como relacional, vermos que estados corporais nunca tendem a se fixar. Corpo e emoção seriam antes um campo aberto a transformações.

As teorias mbya sobre mba'eaxy, que acenam que a doença pode se instalar a qualquer momento, a percepção de que as emoções estão sujeitas a constantes mudanças, as estratégias postas em prática na busca de pôr fim a desconfortos e buscar outras maneiras de reanimar a vida tornam-se produtivas, ao que parece, por se ligarem àquela abertura no modo como o parentesco se organiza no socius.

Aqui nos aproximamos de um outro desenvolvimento importante no campo da antropologia das emoções, que define as emoções como estratégias a serem aprendidas e que são favorecidas pela cultura. $\mathrm{Ou}$ seja, como demonstrou Catherine Lutz para os Ifaluk (LUTZ, 1988), ao se falar de emoções, fala-se do mundo e das relações que se experimenta com outras pessoas. Mais que isto, articulam-se questões interpessoais com o universo moral e da política. Longe de estarem contidas no interior da pessoa, emoções permitem o engajamento em relações e são estratégias da lida em situações sociais. É neste sentido que se definem emoções como song (espécie de"cólera") e metagu ("medo") e o modo como se articulam entre os Ifaluk.

O que gostaria de observar para o contexto guarani em foco é justamente o valor social da relação mesmo quando o que está em questão é o abandono de um contexto relacional. Quando a estratégia de deixar o 
atual contexto de vida se coloca como possibilidade efetiva para alguém, não deixa de ser o universo de relações (entre parentes) que se coloca como alternativa àquela pessoa que pensa em "mudar". Como vimos, se a intenção é declarada, poderá mobilizar sentimentos-agires da parte de parentes corresidentes. De todo modo, na outra ponta, é igualmente o universo de parentes que está no horizonte de uma possível alteração do próprio estado. Noutras palavras, deixam-se parentes sempre para ir atrás de outros parentes.

A experiência (emocional) das relações aqui, sugiro, envolveria um duplo aprendizado. De um lado, aprendem-se os valores éticos e estéticos da vida cotidiana entre parentes que se cuidam. De outro lado, aprende-se a não se perder de vista um horizonte mais estendido no espaço e no tempo para a experiência dessas relações.

Dialogando com a análise de Lutz (ABU-LUGHOD; LUTZ, 1990) sobre como as emoções caracterizam as relações de poder, minha impressão é que as estratégias pessoais aqui descritas de deixar aldeias e buscar outros contextos relacionais produtores de satisfação e saúde não deixam de favorecer uma tendência social igualitária, inclusive em termos de gênero. Mulheres e homens mbya experimentam, na prática, as estratégias de mudar ou "fugir", deslocando-se para outras aldeias, envolvendo-se em novos contextos de convivência, novas relações conjugais, novas atividades, criando novas disposições. O modo como se estrutura o parentesco mbya, isto é, com seu universo social multilocal, abre possibilidades de abandonar relações indesejáveis, de alterar a convivência, de transformar o corpo e as emoções.

\section{Referências}

ABU-LUGHOD, Lila; LUTZ, Catherine A.

(1990). Language and the politics of Emotions. Cambridge: Cambridge University.

ALLARD, Olivier.

(2013). To cry one's distress: death, emotion, and ethics among the Warao of the Orinoco Delta. Journal of the Royal Anthropological Institute, vol. 19, n.3.pp. 545-561.

ALLARD, Olivier.

(2003). Emotions and Relations: a point of view on Amazoniam Kinship. Dissertação de Mestrado, Universityof Cambridge.
ARANHA, Aline de Oliveira.

(2018).Inspirações sobre o fazer(-se) polític@ entre os Guarani-Mbya. Dissertação de Mestrado, USP.

BENITES, Tonico.

(2012). A escola na ótica kaiowa. Rio de Janeiro:Contra Capa.

BENITES, Tonico.

(2014). Rojerokyhina ha roikejevytekohape (Rezando e lutando): o movimento histórico dos Aty Guasu dos Ava Kaiowa e dos Ava Guarani pela recuperação de seus tekoha. Tese 
de Doutorado em Antropologia Social. Museu Nacional, Rio de Janeiro.

CADOGAN, León.

(1992). Diccionario Mbya-Guarani - Castellano. Asunción: Biblioteca Paraguaya de

Antropología/Fundación Leon Cadogan/

CEADUC-CEPAG.

CADOGAN, León.

(1959). Ayvu Rapyta: Textos míticos de losMbyáGuaranídel Guairá. São Paulo: Universidade de São Paulo.

CLASTRES, Pierre.

(1995[1972]). Crônica dos Índios Guayaki. 0 que sabem os Aché, caçadores nómades do Paraguai. Rio de Janeiro: Editora 34.

FAUSTO, Carlos.

(2008). Donos demais: maestria e domínio na Amazônia. Mana, v.14, n.2.pp. 329-366.

FAUSTO, Carlos.

(2002). Banquete de gente: comensalidade e canibalismo na Amazônia. Mana, v.8, n.2.pp. 7-44.

FAUSTO, Carlos.

(2001). Inimigos Fiéis. História, guerra e xamanismo na Amazônia. São Paulo: Edusp.

GARLET, Ivori.

(1997). Mobilidade Mbya: história e significação. Dissertação de Mestrado, PUCRS.

GOW, Peter.

(2000). Helpless: the afective preconditions of Piro social life. In: Joana Overing e Alan Passes (Org.).The Anthropology of love and anger. London/New York: Routledge.pp. 4663.

GOW, Peter.

(1997). 0 parentesco como consciência humana: o Caso dos Piro. Mana, v. 3, n.2.pp. 39-65.

GOW, Peter.

(1991). Of Mixed Blood: Kinship and History in Peruvian Amazonia. 0xford: Clarendon Press.
INSTITUTO SOCIOAMBIENTAL

(2016). Mapa Guarani Continental.

\section{INSTITUTO SOCIOAMBIENTAL}

(2018). Enciclopédia dos Povos Indígenas no Brasil. Disponível em: <http://www. socioambiental.org.br>. Acesso em: 29 maio 2018.

J0Ã0, Izaque.

(2011).JakairaRekoNheypyrũMarangatu Mborahéi: origem e fundamentos do canto ritual jerosy puku entre os Kaiowa de Panambi, Panambizinho e Sucuri'y, MS. Dissertação de Mestrado em História, UFGD.

LADEIRA, Maria Inês.

[1992] 2007. 0 caminhar sob a luz. 0 território mbya à beira do oceano. São Paulo: Unesp.

LEAVITT, John.

(1996). Meaning and feeling in the anthropology of emotions. American ethnologist, v. 23, n.3.pp. 514- 539 .

LUTZ, Catherine.

(1988). Unnatural Emotion: everyday sentiments on a Micronesian Atoll and their challenge to Western Theory. Chicago, University of Chicago Press.

LUTZ, Catherine; WHITE, Geoffrey M.

(1986). The Anthropology of Emotions. Anual Review of Anthropology, v. 15.pp.405- 436.

MACED0, Valéria M.

(2010). Nexos da diferença. Cultura e afecção em uma aldeia guarani na Serra do mar. Tese de Doutorado, PPGAS-FFLCH, USP.

MELIÀ, Bartomeu.

(1990). A Terra sem Mal dos Guarani: Economia e Profecia. Revista de Antropologia, 33: 33-46.

MELIÀ, Bartomeu.

(1991). El Guarani: Experiencia Religiosa. Asunción: CEADUC - CEPAG.

MELLO, Flávia Cristina de.

(2006). Aetchánhanderukuerykarairetarã: Entre deuses e animais: xamanismo, parentesco 
e transformação entre os Chiripá e Mbyá Guarani. Tese de Doutorado, UFSC.

MENDES JUNIOR, Rafael. (2009). Os animais são muito mais que algo somente bom para comer. Dissertação de Mestrado em Antropologia apresentada à Universidade Federal Fluminense.

MENDES JÚNIOR, Rafael.

(2016). A saga rumo ao norte e os outros do caminho: a busca da terra sem mal entre os Guarani contemporâneos. Tese de Doutorado, PPGAS, Museu Nacional, UFRJ.

MONTOYA, Pe. Antonio Ruiz de.

(1876). Vocabulário y Tesoro de laLengua Guarani, ó mas bien Tupi. Viena/Paris: Editora do Visconde de Porto Seguro, Faesy y Frick/ Maisonneuve y Cia.

NIMUENDAJU, Curt Unkel.

(1987) [1914]. As lendas de criação e destruição do mundo como Fundamentos da religião dos Apapocúva-Guarani. São Paulo: HUCITEC; Editora da Universidade de São Paulo.

OVERING, Joana.

(1991). A Estética da Produção: 0 Senso de Comunidade entre os Cubeo e os Piaroa. Revista de Antropologia, n.34.pp. 7-33.

OVERING, Joana; PASSES, Alan. (eds). (2000). The Anthropology of Love and Anger. The Aestheics of Conviviality in Native Amazonia. London: Routledge.

PEREIRA, Vicente Cretton.

(2014).Aqueles que não vemos: uma etnografia das relações de alteridade entre os Mbya Guarani.

PESQUISADORES INDÍGENAS.

(2013). Xondárombaraete. A força do xondáro.

Centro de Trabalho Indigenista/IPHAN/ Comissão Yvy Rupa.

PIMENTEL, SpensyKimita.

(2012). Elementos para uma teoria política kaiowá e guarani. Tese de Doutorado em Antropologia. Universidade de São Paulo.
PIMENTEL, SpensyKimita.

(2006). Sansões e Guaxos - Suicídio Guarani Kaiowá, uma Proposta de Síntese. Dissertação de Mestrado em Antropologia. Universidade de São Paulo.

PISSOLATO, Elizabeth.

(2007). A duração da pessoa: mobilidade, parentesco e xamanismo mbya (guarani). São Paulo: Edunesp.

PISSOLATO, Elizabeth.

2015. Fuga como estratégia: notas sobre sexualidade, parentesco e emoções entre pessoasmbya. Cadernos de Campo.pp.412426.

PISSOLATO, Elizabeth.

(2016). Trabalho, subsistênciae dinheiro: modos criativosna economía mbyacontemporânea. Horizontes Antropológicos. 45: 105-125.

PRATES, Maria Paula.

(2013). Da instabilidade e dos afetos: pacificando relações, amansando Outros. Cosmopolítica guarani-mbya. Tese de Doutorado, UFRGS.

ROSALDO, Michelle.

(1984). Toward an Anthropology of Self and Feeling. In: Richard Seweder e Robert A. Le Vine (Orgs.). Culture Theory. Essays on Mind, Self and Emotion. Cambridge: Cambridge University Press.pp. 137-157.

SANTOS, Lucas Keese.

(2017). A esquiva do xondaro - movimento e ação política entre os Guarani Mbya. Dissertação de Mestrado, USP.

SCHADEN, Egon.

(1962). Aspectos Fundamentais da Cultura Guarani. São Paulo: EPU/EDUSP.

SEEGER, Anthony; DA MATTA, Roberto; VIVEIROS DE CASTRO, Eduardo.

(1979). A construção da pessoa nas sociedades indígenas brasileiras. Boletim do Museu Nacional, n.32.pp. 2-19.

STRATHERN, Marilyn.

(1988). The gender of the gift. Problems with women and problems with society in 
Melanesia. Berkeley e Los Angeles: University of California Press.

SURRALÉS, Alexandre.

(2003). Au coeur du sens: perception, affectivité, action chez les Candoshi. Paris: CNRS Éditions.

TAYLOR, Anne-Christine.

(1996). The Soul's Body and Its States: An Amazonian Perspective of Being Human. The Journal of The Royal Anthropological Institute, v. 2, n. 2.pp. 201-215.

TAYLOR, Anne-Christine; VIVEIROS DE CASTRO, Eduardo.

(2006). Un corps fait de regards. In: Qu-estcequ'un corps? Paris : MuséeduQuaiBranly/ Flammarion.pp. 149-198.

VILAÇA, Aparecida.

(2005). Chronically unstable bodies: reflections on Amazonian Corporalities. Royal Anthropological Institute, v. 11, n.3.pp.445-464.

VILAÇA, Aparecida.

(2002). Making kin out of others in Amazonia. Journal of Anthropological Institute, n.s. 8, v.2.pp. 347-365.
VILAÇA, Aparecida.

(1992). Comendo como Gente: Formas do Canibalismo Wari'. Rio de Janeiro: Editora da UFRJ.

VIVEIROS DE CASTRO, Eduardo.

(1996). Images of nature and society. Annual Review of Anthropology. v. 25.pp. 179-200.

VIVEIROS DE CASTRO, Eduardo.

(1986). Araweté, os deuses canibais. Rio de Janeiro: Jorge Zahar.

WILCE, James M.

(2009). Language and emotion. Cambridge: University Press,

\section{Recebido em}

agosto de 2019

\section{Aprovado em}

dezembro de 2019 